International Journal of Medical Arts 2020; 2 [3]: 668-673.

Available online at Journal Website
https://ijma.journals.ekb.eg/
Main subject [Medicine [Obstetrics]]

Original article

\title{
Effect of Sublingual Misoprostol Prior to Insertion of Intrauterine Device in Women with no Previous Vaginal Delivery
}

\author{
Zeinab Mohammed Saber Elgharabawy [a]; Waleed Ahmed Ayad [b]; Abd Elraouf Mohamad Oun [b]
}

Department of Obstetrics and Gynecology, Port Fouad General Hospital, Ministry of Health, Egypt $[\mathrm{a}]$

Department of Obstetrics and Gynecology, Damietta Faculty of Medicine, Al-Azhar University, Egypt ${ }^{[b]}$

Corresponding author

Zeinab Mohammed Saber Elgharabawy

Email: zeinabmohamedbody@gmail.com

Received at: January 06, 2020; Revised at: April 22, 2020; Accepted at: April 23, 2020; Available online at: April 23, 2020

DOI: 10.21608/ijma.2020.22013.1075

\section{ABSTRACT}

Background: The intrauterine device [IUD] is a safe and effective method of contraception, fear of pain during insertion discourages some providers to recommend IUDs to women with no previous vaginal delivery.

Aim of the work: The aim of the study is to evaluate sublingual misoprostol $200 \mu \mathrm{g}$ on the cervix one hour before IUD insertion; to facilitate IUD insertion in women with tight cervix or in whom did not deliver vaginally.

Patients and Methods: The study was a double blinded randomized controlled trial, compared sublingual 200 $\mu \mathrm{g}$ misoprostol with placebo. The study included 260 cases attended the Gynecology Clinic [Al-Azhar University Hospital] from December 2018 to November 2019. All females signed an informed written consent, and then have been randomly divided into 2 groups using a closed envelope technique. Every female had been asked to take the drug sublingually then return after one hour to insert her IUD. Group A included 130 females who used sublingual misoprostol $200 \mu \mathrm{g}$ [Misotac] and group B included 130 females who took a placebo one hour before IUD insertion [Control group].

Results: IUD and uterine sound insertion was unsuccessful in $8.5 \%$ of group A versus $13.8 \%$ in group $B$ while it was successful in $91.5 \%$ of group A versus $86.2 \%$ in Group B. Among the successful cases, 88[73.9] were easy in group A versus $77[68.8]$ in group B. On the other hand, $31[26.1 \%]$ and $35[31.2 \%]$ were difficult in group A and B respectively. With no significant difference between both groups either in IUD or uterine sound insertion successful or easiness rate $[p=0.17 \& 0.38$ respectively]

Conclusion: Using of misoprostol to facilitate IUD insertion in women with tight cervix, has no role in pain reduction or increase the ease of IUD insertion, although results with misoprostol are superior to placebo, but the different did not reach statistical significance.

Keywords: Sublingual; Misoprostol; Intrauterine Device; Vaginal; Delivery.

This is an open access article under the Creative Commons license [CC BY] [https://creativecommons.org/licenses/by/2.0/]

Please cite this article as: Elgharabawy ZMS, Ayad WA, Oun AM. Effect of Sublingual Misoprostol Prior to Insertion of Intrauterine Device in Women with no Previous Vaginal Delivery. IJMA 2020; 2[3]: 668-673.

* Main subject and any subcategories have been classified according to the research topic. 


\section{INTRODUCTION}

Intrauterine contraception devices [IUCDs] are excellent contraception for females due to a long acting effects in comparison with other contraception methods. In addition, it had a low failure rate $[\sim 1 \%$ in the first year of use] and this rate decrease in following years[1]. These advantages make IUCDs the commonest form of birth control used all over the world. In addition, IUCDs have no action needed at time of intercourse, no systemic side effects, have reversible action once removed and return to fertility very rapid. In nulliparous females and who did not deliver vaginally before, there is stenotic cervix and insertion may be painful and difficult[2].

There are efforts to ease the insertion of all types of IUDs; some health practitioner appointed to Misotac [misoprostol], to females who want to insert IUCD to facilitate the insertion[3]. Misoprostol is a synthetic [PGE1] analogue, could be used sublingually, vaginally, orally or rectally. Uterine contractions, cervical changes and ripening, facilitation of trans-cervical procedures are the actions of misoprosto|[4]. Sublingual misoprostol showed elevation of plasma concentration in comparison to vaginal administration. Sublingual misoprostol more effective for cervical priming in comparison with oral route and similar effect as vaginal route[5].

\section{AIM OF THE WORK}

The aim of the study was to evaluate sublingual misoprostol $200 \mu \mathrm{g}$ on the cervix one hour before IUD insertion. To facilitate IUD insertion in women with tight cervix or in whom did not deliver vaginally.

\section{PATIENTS AND METHODS}

This research was a double blinded randomized clinical trial, comparing sublingual [200] $\mu \mathrm{g}$ misoprostol with the placebo to help in the insertion of IUCDs. This work included 260 females who were selected to the Clinic of Gynecology in Al-Azhar University Hospital from December 2018 to November 2019 after applying the inclusion criteria and acceptance of IUCD as contraception of choice, all females had signed a properly knowledgeable written consent. After acceptance of IUCD as contraception of choice, females have been randomly divided into two groups using a closed envelope, the doctor did no longer realize the randomization if misotac or placebo as every female asked to take an envelope whether misoprostol or placebo and took it sublingually for twenty minutes then turn back after one hour to do the procedures and insert the IUCD.

Group A for misoprostol [as Misotac $200 \mu \mathrm{g}$ ], and Group B for a placebo.

Inclusion criteria were: Any age during the child bearing period [over 18], any parity with no history of vaginal delivery, no history of previous IUD insertion.

Exclusion criteria were: any symptoms of female genital tract infection, allergy to misoprostol, pregnant female, history of vaginal delivery, abnormal uterine bleeding, contraindication for insertion as myomas or congenital uterine anomalies.

Sample size calculation: The sample size had been calculated using the following formula:

$$
n=\left[\frac{Z_{\alpha / 2}+Z_{\beta}}{\mathrm{P}_{1}-\mathrm{P}_{2}}\right]^{2}\left(\mathrm{p}_{1} \mathrm{q}_{1}+\mathrm{p}_{2} \mathrm{q}_{2}\right)
$$

Where: $n=$ sample size, $Z a / 2=2.576$ [The critical value that divides the central $99 \%$ of the $Z$ distribution from the $1 \%$ in the tail], $Z \beta=1.96$ [The critical value that separates the lower $5 \%$ of the $Z$ distribution from the upper $80 \%$ ], P1 $=$ Proportion of successful insertion with misoprostol $=98.6 \%, \mathrm{P} 2=$ proportion of successful insertion without misoprostol $=86.1 \%$, and $q=1-p$. So, by calculation, the sample size is equal to 130 subjects per group; 260 subjects tota[[6].

Patient preparation included history taking, clinical [general, vaginal, vaginal and bimanual examination were done in these patients to exclude any reason for exclusion criteria]. Other investigations included basic vaginal ultrasound, and pregnancy test [if not menstruating].

The technique for ICUD insertion: female put in a lithotomy position. Sterile Cusco's used to visualize the cervix. Sterilization had been achieved with antiseptic solution. Uterine sound had been inserted to evaluate the direction of the uterus and length with a vulsellum used to make a traction on the cervix. Then, IUCD had been inserted in uterine cavity. TVS was done after insertion to check the correct insertion of the IUCD. We assess pain during the insertion by subjective numeric rating scale from zero to ten recorded by the female and visual analog 
scale recorded by the doctor who inserted the IUCD.

In addition, the other variables studied were: difficulty and pain during insertion of IUCD, unsuccessful insertion and side effects [ fever, pain, bleeding, nausea, and vomiting]. Four weeks after IUCD insertion, pain, bleeding, displacement, expulsion and perforation, were checked for and documented.

Statistical analysis: Data energized to the computer and analyzed using the software package [IBM SPSS] version 22. Qualitative data also described using number and percent, median [min. and max.] for non-parametric data and mean, standard deviation for parametric data after testing normality by Kolmogrov-Smirnov test. Significance of the recorded results had been judged at the [0.05] level.

\section{RESULTS}

In the present study, there were no significant difference between both groups in age, gravidity, parity, BMI \& associated medical disorders [ $p=0.11$, $0.54,0.15,0.65 \& 0.52$ respectively] [Table 1].

In group A, 119 [91.5\%], uterine sound insertion was successful versus 112 [86.2\%] in group B, without significant difference between both groups $[p=0.17]$ [Table 2]. In comparison of uterine sound insertion difficulty between studied groups there is no significant difference between both groups $[p=0.38$ ] [Table 3].
IUD was unsuccessful in $8.5 \%$ of group $A$ versus $13.8 \%$ in group $B$ while it was successful in $91.5 \%$ of group A versus $86.2 \%$ in Group B without significant difference between both groups [ $p=0.17]$ [Table 4].

In comparison by numerical pain scale among cases in group $A$, the majority [34.6\%] had no pain, $33.07 \%$ had mild pain, $19.2 \%$ had moderate pain and only $4.6 \%$ had severe pain. While in group $B$, the majority [34.6\%] had mild pain, $24.6 \%$ had no pain, $21.5 \%$ with moderate pain and only $5.38 \%$ with severe pain. Without significant difference between both groups [Table 5].

In this study, there was significantly higher incidence of nausea, vomiting, fever and pelvic pain in group $A$ than group $B[p=0.001,0.02,0.002,0.003$ respectively]. As among our cases, no side effects were reported in $66.2 \%$ in group $A$ versus $96.2 \%$ in group $B$, while $11.5 \% \& 1.5 \%$ had nausea, $3.8 \%$ versus $0 \%$ had vomiting, $6.9 \%$ versus $0 \%$ had fever and $11.5 \%$ versus $2.3 \%$ had Pelvic pain in group $A \&$ $B$ respectively [Table 6].

Four weeks later, no significant difference between both groups in displacement, expulsion, pain, bleeding [ $\mathrm{p}=1 \& 1 \& 0.98 \& 0.84$ respectively]. As $1.6 \%$ versus $89 \%$ had displacement $\& .84 \%$ versus $0 \%$ had expulsion \& $12.6 \%$ versus $12.5 \%$ had pain and $5.04 \%$ versus $4.46 \%$ had bleeding in group A\&B respectively [Table 7].

Table [1]: Demographic and obstetric history between studied groups.

\begin{tabular}{|l|c|c|c|}
\hline & $\begin{array}{c}\text { Group [A] } \\
\mathbf{N}=130[\%]\end{array}$ & $\begin{array}{c}\text { Group B } \\
130[\%]\end{array}$ & Significance TEST \\
\hline Age/years & $29.68 \pm 5.24$ & $30.85 \pm 6.46$ & $\mathrm{t}=1.6 ; \mathrm{p}=0.11$ \\
\hline Gravidity & $1.99 \pm 0.88$ & $2.06 \pm 0.95$ & $\mathrm{t}=0.61 ; \mathrm{p}=0.54$ \\
\hline Parity & $1.82 \pm 0.56$ & $1.68 \pm 0.85$ & $\mathrm{t}=1.45 ; \mathrm{p}=0.15$ \\
\hline BMI[Kg/m $\left.\mathbf{m}^{2}\right]$ & $27.67 \pm 4.69$ & $27.94 \pm 4.9$ & $\mathrm{t}=0.45 ; \mathrm{p}=0.65$ \\
\hline Associated medical disorders & $\mathrm{n}[\%]$ & $\mathrm{n}[\%]$ & $\mathrm{x}^{2}=0.42 ; \mathrm{p}=0.52$ \\
-ve & $124[95.4]$ & $126[96.9]$ & \\
+ve & $6[4.6]$ & $4[3.1]$ & \\
\hline
\end{tabular}

t: Student t test $X^{2}$ :chi-Square test

Table [2]: uterine sound insertion success between studied groups.

\begin{tabular}{|l|c|c|c|}
\hline Uterine sound insertion & Group $\mathrm{A}[\mathrm{n}=130]$ & Group $\mathrm{B}[\mathrm{n}=130 \%]$ & test of significance \\
\cline { 1 - 3 } Successful & $119[91.5 \%]$ & $112[86.2 \%]$ & $\mathrm{X} 2=1.90$ \\
$\mathrm{y}$ Failure & $11[8.5 \%]$ & $18[13.8 \%]$ & $\mathrm{p}=0.17$ \\
\hline
\end{tabular}

Table [3]: uterine sound insertion difficulty between studied groups.

\begin{tabular}{|l|c|c|c|}
\hline Successful uterine sound insertion & Group A [n=119] & Group B [n=112] & test of significance \\
\hline Easy & $88[73.9]$ & $77[68.8]$ & $\begin{array}{c}\mathbf{x}=1.90 \\
\mathrm{p}=0.38\end{array}$ \\
\hline Difficult & $31[26.1]$ & $35[31.2]$ & \\
\hline
\end{tabular}


Table [4]: IUD insertion success between studied groups.

\begin{tabular}{|c|c|c|c|}
\hline IUD insertion & $\begin{array}{l}\text { Group A } \\
{[\mathrm{n}=130]}\end{array}$ & $\begin{array}{c}\text { Group B } \\
{[n=130]}\end{array}$ & test of significance \\
\hline Failed & $11[8.5]$ & $18[13.8]$ & \multirow{2}{*}{$\begin{array}{c}x 2=1.90 \\
p=0.17\end{array}$} \\
\hline Successful & $119[91.5]$ & $112[86.2]$ & \\
\hline
\end{tabular}

$\mathrm{X}$ :chi-Square test

Table [5]: comparison of Numeric pain scale between studied groups.

\begin{tabular}{|l|c|c|c|}
\hline \multicolumn{1}{|c|}{ Numeric pain scale } & $\begin{array}{c}\text { Group A } \\
\mathrm{n}=130[\%]\end{array}$ & $\begin{array}{c}\text { Group } \mathrm{B} \\
\mathbf{1 3 0 [ \% ]}\end{array}$ & test of significance \\
\hline No & $45[34.6]$ & $32[24.6]$ & $\mathrm{P}=0.14$ \\
\hline Mild & $43[33.07]$ & $45[34.6]$ & $\mathrm{P}=0.53$ \\
\hline Moderate & $25[19.2]$ & $28[21.5]$ & $\mathrm{P}=0.47$ \\
\hline Severe & $6[4.6]$ & $7[5.38]$ & $\mathrm{P}=0.69$ \\
\hline
\end{tabular}

Table [6]: side effects distribution between studied groups.

\begin{tabular}{|l|c|c|c|}
\hline \multicolumn{1}{|c|}{ Side effects } & $\begin{array}{c}\text { Group A } \\
{[n=130]}\end{array}$ & $\begin{array}{c}\text { Group B } \\
{[n=130]}\end{array}$ & Test of significance \\
\hline No side effects & $86[66.2]$ & $125[96.2]$ & $\chi^{2}=38.25 ; p<0.001^{*}$ \\
\hline Nausea & $15[11.5]$ & $2[1.5]$ & $\chi^{2}=10.64 ; p=0.001^{*}$ \\
\hline Vomiting & $5[3.8]$ & $0[0.0]$ & $\chi^{2}=5.1 ; p=0.02^{*}$ \\
\hline Fever & $9[6.9]$ & $0[0.0]$ & $\chi^{2}=9.3 ; p=0.002^{*}$ \\
\hline Pelvic pain & $15[11.5]$ & $3[2.3]$ & $\chi^{2}=8.59 ; p=0.003^{*}$ \\
\hline
\end{tabular}

$x^{2}$ :chi-Square test *statistically significant [ $\left.p<0.05\right]$

Table [7]: Comparison of follow up results after 4 weeks between studied groups.

\begin{tabular}{|l|c|c|c|}
\hline \multicolumn{1}{|c|}{ Four weeks follow up } & $\begin{array}{c}\text { Group A } \\
{[\mathrm{n}=119]}\end{array}$ & $\begin{array}{c}\text { Group B } \\
{[\mathrm{n}=112]}\end{array}$ & Test of significance \\
\hline Displacement & $2[1.6]$ & $1[0.89]$ & $\mathrm{p}=1.0$ \\
\hline Expulsion & $1[0.84]$ & 0 & $\mathrm{p}=1.0$ \\
\hline Perforation & 0 & 0 & \\
\hline Pain & $15[12.6]$ & $14[12.5]$ & $\mathrm{X}^{2}=0.001 ; \mathrm{p}=0.98$ \\
\hline Bleeding & $6[5.04]$ & $5[4.46]$ & $\mathrm{X}^{2}=0.04 ; \mathrm{p}=0.84$ \\
\hline
\end{tabular}

$\mathrm{X}^{2}$ : chi-Square test FET: Fisher exact test

\section{DISUCSSION}

Results of the current work revealed that, the use of misoprostol to facilitate IUCD insertion is somewhat better than placebo. However, the differences did not reach statistical significance.

Many studies did not show any improvement in facilitation of insertion recorded by the physicians with the use of misoprostol. However, the use of misoprostol usually associated with patient comfort.

Several other studies ${ }^{[7,11]}$ did not demonstrate enhancement in facilitation of insertion as in our study. Our results were in harmony with another double-blinded RCT by Alton et al. who compared two tablets of misoprostol vaginally with placebo three hours prior to insertion of IUCD in 270 cases. No changes have been recorded in failure of insertion in the group of misoprostol when compared the group of placebo[7].

Also, one research used misoprostol after failure of insertion tried in eight patients. Insertion has been success in all eight patients as the use of misoprostol vaginally day prior to the insertion. Similarly, researches are needed to decide if benefit overweigh the risks and side effects[8].

In agreement with our study, another RCT by Lyus et al. compared two regimens, buccal misoprostol with placebo prior to insertion of IUCD in forty nulliparous females. No changes have been recorded for pain in the group of misoprostol and the placebo group[9]. In addition, our study agrees with a double-blind, multicenter randomized clinical research by Dijkhuizen et al. who asked females to take two tablets of misoprostol or a placebo [vaginally], three hours prior to insertion of IUCD. There has been a non-significant result in improving 
pain at IUD insertion by women in the misoprostol group when compared with controls [10].

Also, we are supported by a randomized clinical trial of Scavuzzi et al. who randomized females to obtain two tablets of misoprostol, or placebo, vaginally, one hour prior to insertion. This study did not show any significant difference in patientreported pain[11].

And similarly, Edelman et al. noted in their double-blind, randomized clinical trials of misoprostol, there is more nausea in the misoprostol group than in controls [7]. Similar findings were observed by another double-blinded study of Alton et al. who compared two tablets of vaginal misoprostol with placebo prior to insertion of IUCD in 270 females. Interestingly, side effects as nausea, headache, and shivering have been more reported in the misoprostol group [3].

Our results were supported by a double-blind, randomized clinical trials by Heikinheimo et al. who comparing misoprostol to placebo. There has been a significant rise in side effects in misoprostol compared with the placebo group as nausea, abdominal pain and diarrhea [12].

On the other side, a recent meta-analysis carried out by Tassi et al.[13] concluded that, misoprostol use is associated with a reduction in a filature rate of the IUCD insertion for females with previous cesarean delivery or with previous IUCD insertion failure. These data suggested a reasonable choice specific for such categories of females. However, its use is associated with increased side effects, and there was a heterogenous pattern of its efficacy among different studies included in this meta-analysis. They eventually, are not able to support its routine use prior to IUCD insertion.

In addition, Ashour et al.[14] reported that, premedication with vaginal dinoprostone or misoprostol lead to significant reduction of pain during IUCD insertion. Clinicians reported more easiness with premedication of either drugs, and women in both groups were satisfied with IUCD insertion.

Furthermore, Rasheedy et al.[15] reported that, vaginal misoprostol prior to IUCD insertion in parous females with previous failure increased the success rate, particularly in females with previous caesarean section.
The different route of administration of misoprostol could explain the controversy of the results between the current study and others used it by vaginal route and reported a significant beneficial effect.

\section{Conclusion}

Misoprostol, has insignificant role in reduction of pain or facilitation of IUCD insertion. In females with narrow cervix or in who didn't deliver vaginally.

\section{Financial and Non-Financial Relationships and Activities of Interest}

None declared by the authors

\section{REFERENCES}

1. Lohr PA, Lyus R, Prager S. Use of intrauterine devices in nulliparous women. Contraception. 2017 Jun; 95(6):529-537. [DOI: 10.1016/j.contraception. 2016. 08.011].

2. Mansy AA. Does sublingual misoprostol reduce pain and facilitate IUD insertion in women with no previous vaginal delivery? A randomized controlled trial. Middle East Fertil Soc J. 2018; 23: 72-76. [DOI: 10.1016/j.mefs.2017.08.007].

3. Alton TM, Brock GN, Yang D, Wilking DA, Hertweck SP, Loveless MB. Retrospective review of intrauterine device in adolescent and young women. J Pediatr Adolesc Gynecol. 2012 Jun;25(3):195-200. [DOI: 10.1016/j.jpag.2012.01.005].

4. Hofmeyr GJ, Gülmezoglu AM, Pileggi C. Vaginal misoprostol for cervical ripening and induction of labour. Cochrane Database Syst Rev. 2010 Oct 6;2010(10):CD000941. [DOI: 10.1002/14651858. CD000941.pub2].

5. Sääv I, Aronsson A, Marions L, Stephansson O, Gemzell-Danielsson K. Cervical priming with sublingual misoprostol prior to insertion of an intrauterine device in nulliparous women: a randomized controlled trial. Hum Reprod. 2007 Oct; 22 (10):2647-52. [DOI: 10.1093/humrep/dem244].

6. Abdellah MS, Abbas AM, Hegazy AM, El-Nashar IM. Vaginal misoprostol prior to intrauterine device insertion in women delivered only by elective cesarean section: a randomized double-blind clinical trial. Contraception. 2017 Jun; 95(6):538-543. [DOI: 10.1016/j.contraception.2017.01.003].

7. Edelman AB, Schaefer E, Olson A, Van Houten L, Bednarek P, Leclair C, Jensen JT. Effects of prophylactic misoprostol administration prior to intrauterine device insertion in nulliparous women. Contraception. 2011 Sep;84(3):234-9. [DOI: 10.1016/j.contraception.2011.01.016]. 
8. Lopez LM, Bernholc A, Zeng Y, Allen RH, Bartz D, O'Brien PA, Hubacher D. Interventions for pain with intrauterine device insertion. Cochrane Database Syst Rev. 2015 Jul 29;(7):CD007373. [DOl: 10.1002/14651858.CD007373.pub3].

9. Lyus R, Lohr P, Prager S; Board of the Society of Family Planning. Use of the Mirena LNG-IUS and Paragard CUT380A intrauterine devices in nulliparous women. Contraception. 2010 May; 81 (5): 367-71. [DOI: 10.1016/ j.contraception. 2010. 01.010].

10. Dijkhuizen K, Dekkers OM, Holleboom CA, de Groot CJ, Hellebrekers BW, van Roosmalen GJ, Janssen CA, Helmerhorst FM. Vaginal misoprostol prior to insertion of an intrauterine device: an RCT. Hum Reprod. 2011 Feb; 26 (2):323-9. [DOI: 10.1093/ humrep/deq348].

11. Scavuzzi A, Amorim M, Acioly D. 0829 Misoprostol prior to insertion of intrauterine device in nullipara: $A$ randomized controlled trial. A pilot study. Int J Gynecol Obstetr 2009; 107: S330-S330. [DOI: 10. 1016/ S0020-7292(09)61202-9]

12. Heikinheimo $O$, Inki $P$, Kunz $M$, Parmhed $S$, Anttila AM, Olsson SE, Hurskainen $R$, GemzellDanielsson K. Double-blind, randomized, placebocontrolled study on the effect of misoprostol on ease of consecutive insertion of the levonorgestrelreleasing intrauterine system. Contraception 2010 Jun; 81 (6): 481-6. [DOI: 10.1016/j.contraception. 2010. 01.020].
13. Tassi A, Parisi N, Londero AP. Misoprostol administration prior to intrauterine contraceptive device insertion: a systematic review and metaanalysis of randomized controlled trials. Eur $\mathrm{J}$ Contracept Reprod Health Care 2020 Feb;25(1):7686. [DOI: 10.1080/13625187.2019.1706079].

14. Ashour ASA, El Sharkawy M, Ali AS, Keshta NHA, Shatat HBAE, El Mahy M. Comparative Efficacy of Vaginal Misoprostol vs Vaginal Dinoprostone Administered 3 Hours Prior to Copper T380A Intrauterine Device Insertion in Nulliparous Women: A Randomized Controlled Trial. J Pediatr Adolesc Gynecol. 2020 Apr 21: S1083-3188(20)30206-0. [DOI: 10.1016/j.jpag.2020.04.004].

15. Rasheedy R, Tamara TF, Allam IS, Abbas AM, Essam El-Din Abd El Salam N, Ferhad Ahmed A. Vaginal misoprostol before copper IUD insertion after previous insertion failure: a double-blind, placebocontrolled, parallel-group, randomized clinical trial. Eur J Contracept Reprod Health Care. 2019 Jun; 24 (3): 222-226. [DOI: 10.1080/13625187. 2019. 1610871]. 